\title{
Study on Tourism Landscape Planning of Rural Leisure Agriculture
}

\author{
Zhuyu Wang ${ }^{1, a}$ \\ ${ }^{1}$ Haikou College of Economics, Haikou, Hainan, 571123 \\ ${ }^{a}$ email
}

Keywords: Leisure Agriculture Tourism, Tourism Resource, Agriculture Culture

\begin{abstract}
With the acceleration of urbanization process and the improvement of social and economic development, leisure agriculture attracts more and more urban consumers. At the same time, the development of leisure agriculture and rural tourism has promoted me national agricultural development strategy, strategic emerging industries are the construction of modern agriculture and promote new socialist countryside construction, an important way to build a harmonious society. He led the local farmers' income, rural village appearance change and expands the industrialization of agriculture park feature. In this paper, the sea area surrounding the crater and village tourism resources Case exploratory analysis of the functional role of leisure agriculture development for local farmers and urban residents, leisure agriculture and traditional agriculture, tourism and travel resources on the relationship between leisure agriculture farming culture planning and development of the impact made by the system.
\end{abstract}

\section{Introduction}

Over the last decade, along with the rapid development of society and people's living standards improve, people's living environment quality have become increasingly demanding, engaged in the similar style of reinforced concrete high-rise residential and boring streets, the city people's income increase in lifestyle and consumption structure has undergone new changes, expansion of city size, overcrowding, air pollution, overcrowding the city's attractions, these factors have contributed to the city people on holiday temporarily leaving the big cities, the natural beauty, the environment quiet suburbs sightseeing Leisure Travel. In the fast-paced high-intensity work pressure and life of urban dwellers dream of a kind of paradise leisurely lifestyle, the need for pressure release and debugging physical and mental health and leisure tourism has gradually become the universal needs of the people.

Leisure agriculture and rural tourism combination is in line with the needs of people. China is a large agricultural country, the development of tourism agriculture, improve the economic value added of the primary industry of agriculture, improving the quality of life of farmers, not only in line with China's national conditions, but also to promote the development of Area environment, both to increase the added value of the agricultural park, increase Agricultural income garden; but also promote the development of the entire regional economy. Subject of this article Haikou crater surrounding tourism resources and Villages Case summary and discussion of practical and theoretical issues, tourism and leisure agriculture and rural tourism development, according to the rural reality, the planning and design of agro-leisure theme of rural landscape will be the study.

\section{The Design Principles of Rural Leisure Agriculture Landscape Planning}

Rural agricultural areas is a form of regional economic organization, its landscape planning and design must first have the overall concept, landscape planning and design requires the use of multi-disciplinary knowledge, the landscape as a whole to think and design, function and achieve coordinated development of ecological achieve overall optimal use.

Rural Landscape should first adhere to when developing planning local guidelines, should make full use of local native element, to maintain local and authenticity rural resources, and create a rustic image, for example, maximize the use of locals architecture; greening the choice of species they use native plants, not to engage in large-scale construction projects, try to keep the original structure of 
rural landscape; introduction of appropriate incentive measures to keep local agricultural and cultural patterns.

The reason why rural village called because of its original natural features, to a rustic natural agricultural landscape, terraced terrain, colorful hybrid forest and other natural landscape elements oriented, moderate plan design art ecology.

As the role of natural and anthropogenic disturbances, and landscape ecosystem over time and will continue to occur in the structure and function changes that affect the tourism landscape of healthy and sustainable development. Therefore, in landscape planning and design must follow the principle of sustainability.

Ecological aesthetic principles include natural beauty, ecological relationships harmonious beauty and artistic beauty and environmental integration, it emphasizes man rule, symmetry, form, lines, etc. In sharp contrast, the highest aesthetic guidelines for landscape planning and design.

\section{The Research and Analysis of Regional Resources}

Saddle Ridge crater Xiuying District located in Haikou City, Hainan Province, Stone Town territory, 15 kilometers away from the city, Xiuying District is one of four districts of the city of Haikou. Located in the northwest of the city of Haikou, capital of Hainan Province, east Longhua District, Chengmai County, west, south and bordering Ding'an, north of Qiongzhou Strait, a total area of 511.5 square kilometers. Mainly the United States and the village community, the United States consistently Village, United States Takamura.

Xiuying District located in Haikou City, Hainan Province, Stone Town, only 15 kilometers away from the city, West Expressway turn green corridor up, Ring Expressway through the park. Transport facilities, public transport links and more.

Crater near the village of US society, the United States and US penetration filial village, living environment and human landscape of other villages very unique and beautiful, unique architectural style cottage, lava and other materials are local. The village still retains part of volcanic rocks and volcanic material cut ancient houses built craft constructed buildings, such as volcanic stone houses, stone walls, Shimen, Stone Road, ancestral halls, temples, and other monuments (such as: anti-Japanese wall, Fuxing floor), Kaoshanchishan utensils ancient and rich culture of the volcano.

Locals take advantage of the unique volcanic region, the local volcanic rock made of a variety of household items such as: stone, mortar, stone trough, squeezed sugarcane juice machine, pier, stone cylinder and the like.

Living customs volcanic areas: diet custom, custom holiday, Lent, the public stage, Marriage.

\section{The Rural Landscape Planning Practice of Leisure Agriculture - A Case Study of Port Development Status of the Volcano}

Leiqiong Haikou volcanoes world geological park Quaternary volcanoes are geological heritage landscape theme, and the fusion of tropical ecological landscape, volcanic material and non-material cultural heritage, sightseeing, entertainment, science expedition, ecological and cultural tourism in one of the tropical island city volcanic park.

Haikou Shishan volcanoes world geological park territorial cutting a rift mafic volcanic activities geological relics, scenic main geological heritage, scenic volcanic collar, saddle collar volcanoes, volcanic landscape. Although the resort features restaurants and shopping outlets and other science museums, but the development of tourism resources is still insufficient, efforts to develop small, for tourists to enjoy the place is too small to attract tourists to come to watch.

Management and supervision work is not fully implemented, that due to the increase of tourists and visitors not comprehensive quality caused a lot of interest within the crater have been destroyed.

The vast majority of the park has been opened resorts have established their own system of explanations, so that visitors refreshing, praise volcanic park implement the basic national policy of scientific concept of development. However, due to the management system, management system, 
staffing, supervision and inspection problems, leading to scientific explanations, science popularization work is still the weak link in the volcanic park.

The traffic is not convenient, to reach the crater little green car, visitors travel inconvenient, this is an important factor in reducing the amount of tourists.

Haikou happy farm consists of three sub-tropical paradise Forest Park Limited investment, following Earthly Paradise Bird's Nest Resort Haikou another fine tourism and leisure projects, boutique farmhouse other homes. It's strange architectural culture crater area for the carrier and volcanic village rich folk culture of the essence, to provide both ecological and modern, both simple and sophisticated leisure life.

Tree-lined, simple natural volcanic manor, typical volcanic cuisine, original volcanic folk, handmade tofu eating, drinking rice wine, listen octave volcano, rural scenery intoxicated. Cycling tour green slow way street, watching outdoor movies in the summer evening, take a sightseeing tour of small wasp volcano ancient villages, held in the distinctive square happy idyllic wedding, enjoy a leisurely leisure time.

US society is a natural village Xiuying District, Haikou City, Hainan Province, Stone Town Shi tea village, located Leiqiong world geological park planning area, located south of Saddle Ridge crater, convenient transportation, good ecological environment, scenic, is distinctive volcano village. US agency village 172, 832 people, the village had 21 farms and orchards orchard courtyard, village planted precious tropical forests, especially in the "national treasure pear" most prestigious, it is the famous pear village.

According to local conditions, it highlights the characteristics of the volcano, the United States as a resort village community planning. In the village environment, focusing on promoting green environment, health and clean technology, optimize the layout, residential landscaping, construction and other supporting services to strengthen. By drilling rule slope, improve agricultural production conditions, the development of efficient agriculture and selenium-rich fruit, the establishment of agricultural sightseeing garden industry. Building green leisure slow system, accelerate the development of tourism driven farmhouse. Efforts to increase farmers' income, improve production conditions of farmers, improve the quality of life of farmers. Increase training, nurture new farmers to achieve economic development and simultaneously improve the overall quality of the villagers. Through various efforts to bring the United States into a village community economic development, improve democracy, scientific and technological advancement, cultural prosperity, social harmony and upgrade the texture of life of the people "rich farmers, the village beauty, all facilities, good habits, good mechanism," the comprehensive well-off village and tourist destination to attract tourists.

Industrial park construction has development of agricultural tourism experience; the introduction of elements of tourism, construction greenway slow system, the development of peasant music, to create "public recreation homes, vacation paradise.

\section{The Development of Rural Tourism Advantages and Prospects}

Chinese vast territory and natural type is complex, forming a diverse rural agricultural landscape. Nationally, can be divided into northern rainfed agricultural landscape, agricultural landscape paddy south, northwest of grassland animal husbandry and irrigation oases, Southwest Mountain plateau landscape agriculture, animal husbandry, agriculture alpine landscape, coastal landscape modern agriculture and so on. These rural agricultural landscape resources are different characteristics for the development of Chinese rural tourism provides excellent conditions.

China is a large agricultural country, agriculture is ancient. A long history of agriculture, rich farming culture, is a good basis for the development of cultural tourism in rural agriculture. China is a multi-ethnic country, there are 56 ethnic distribution in the vast countryside, particularly in the western region for the minority concentrated area. National customs, culture, ethnic habits, national life, national construction, national festivals and other colorful, unique resources, the development of rural folk culture tourism.

With the rapid development of the national economy and urbanization, urban scale, population 
has great growth, deteriorating working and living environment, leading to more intense urban residents to the outskirts of rural tourism wishes. Coupled with the increase in urban incomes, increased vacation time, to improve traffic conditions and changing consumer attitudes, both for the development of rural tourism to provide a broad market.

China is a large agricultural country and farmers, to solve the "three rural" issue is the development of Chinese social economy, the top priority of building a moderately prosperous society, causing a high degree of the CPC Central Committee and all levels of government. Solve the "three rural" issue, first of all to people-oriented, in order to increase farmers' income as the center, adjust and optimize the agricultural structure, the transfer of rural surplus labor. The agri-tourism and rural tourism, it is the adjustment of agricultural structure, to achieve combination of agriculture and tourism, a new way of combining industry and tertiary industries, the development of rural economy, a new bright spot. China has the resources to develop rural agricultural tourism, huge market prospects. The future of China is not only a tourist destination but also rural agricultural tourism should become the world's major powers. Looking to the future, rural tourism and agri-tourism will be shown on Chinese soil, its vitality, to develop into a very viable new industry.

\section{Conclusion}

Leisure agriculture is a combination of production, life and ecology, "Sansei one" of the industry, which aims to utilize rural resources, combined with tourism and leisure, promote agricultural restructuring, increase rural employment, increase farm income, rural economic prosperity, promote rural development.

The ultimate goal of development is to promote agriculture and leisure agriculture and rural area development area, development of leisure agriculture is one of the means to revitalize the agricultural area, which is designed to help address the small scale, and industry and more agricultural employment and aging agricultural management dilemma way. Therefore, development is not the ultimate goal of leisure agriculture and leisure area of the farm, but with the push of leisure agriculture industry to boost the overall development of rural areas.

\section{Acknowledgements}

2013 Hainan Philosophy and Social Sciences project "Employment and Income small town farmers empirical analysis of rural tourism in Hainan," item number: HNSK (JD) 13-06.

2015 the university key issues of Haikou College of Economics " Leisure Tourism in Luoshai village, Baisha Township, Hainan Province ", project number: HJKZ15-08.

\section{References}

[1] Wang Zhuyu. Leisure Tourism in Hainan agricultural science of Anhui Agricultural Sciences, 01, 2014.

[2] Jiang Weibing, Chen Yu, Jiang Peng. On Sightseeing Agriculture Park Landscape Character Chinese Garden, 03, 2003.

[3] Wang Yuncai, Liu Binyi. Chinese rural landscape and Rural Landscape Planning [J]. Chinese gardens, 2003, (1): 56-59.

[4] Wang Jun. Principle and Method Landscape Ecological Planning [J]. Resource Sciences .1999, 21 (2): 71-76.

[5] Zhou Qiliang, Wan Ling. Wood and other Tropical Leisure Agriculture Resources Development Model [J]. Anhui Agricultural Sciences, 2011.39 (13): 7989-7991.

[6] Tong Nianqing. Study of leisure agriculture and rural tourism with international norms standards [J]. Hunan Agricultural Sciences, 2012 (10): 36-38. 
[7] Zheng Jianxiong, Guo Huancheng, Chen Tianzhu. Leisure agriculture and rural tourism development [M] Xuzhou: China Mining University Press, 2005. 8.

[8] Chen Xianghong. Study Chinese Tourism Development in Leisure Times [J]. Chinese market. 2007, (48).

[9] Wei Wei. Development of rural tourism and leisure Agriculture Tourism [J]. suburban small towns. 2009, (7).

[10] Liu Jinghong. Hainan agricultural science and leisure tourism development [N]. China Tourism News .2011. 